\title{
Activation of G-protein-coupled receptor 40 attenuates the cisplatin-induced apoptosis of human renal proximal tubule epithelial cells
}

\author{
SEONG KWON MA ${ }^{1,4}$, SOO YEON JOO ${ }^{1}$, HOON-IN CHOI $^{1}$, EUN HUI BAE ${ }^{1}$, \\ KWANG IL NAM ${ }^{2,4}$, JONGUN LEE ${ }^{3}$ and SOO WAN KIM ${ }^{1}$ \\ Departments of ${ }^{1}$ Internal Medicine, ${ }^{2}$ Anatomy, and ${ }^{3}$ Physiology, Chonnam National University Medical School; \\ ${ }^{4}$ Research Institute of Medical Sciences, Chonnam National University, Gwangju 501-757, Republic of Korea
}

Received March 31, 2014; Accepted July 25, 2014

DOI: $10.3892 / \mathrm{ijmm} .2014 .1874$

\begin{abstract}
G-protein-coupled receptor 40 (GPR40) is known to play a role in the regulation of fatty acids, insulin secretion and inflammation. However, the pathophysiological roles of GPR40 in kidney disease have not yet been identified. In the present study, we investigated the expression of GPR40 during cisplatin-induced kidney injury using male Sprague-Dawley rats that were treated with $8 \mathrm{mg} / \mathrm{kg}$ cisplatin. Control rats were treated with saline. Following treatment with cisplatin, the protein expression of GPR40 in the kidneys was decreased in association with an increase in serum creatinine levels and the $\mathrm{Bax} / \mathrm{Bcl}-2$ expression ratio. To further investigate the function of GPR40, the human renal proximal tubule epithelial cell line (HK-2) was cultured with cisplatin in the absence or presence of GW9508, a selective GPR40 agonist. Pre-treatment of the HK-2 cells with GW9508 attenuated the decrease in cell viability induced by treatment with cisplatin. Treatment with cisplatin increased the number of cells with condensed nuclei, which was ameliorated by GW9508 pre-treatment. TUNEL assay also revealed that pre-treatment with GW9508 ameliorated cisplatin-induced apoptosis. Treatment with cisplatin increased the $\mathrm{Bax} / \mathrm{Bcl}-2$ expression ratio and cleaved caspase-3 expression, and promoted the activation of nuclear factor- $\mathrm{\kappa B}$ $(\mathrm{NF}-\kappa \mathrm{B})$. These changes were attenuated by pre-treatment with GW9508. The cisplatin-induced generation of reactive oxygen species (ROS) and the activation of the Src/epidermal growth factor receptor (EGFR)/extracellular signal-regulated kinase (ERK) pathway were also counteracted by pre-treatment with GW9508. Thus, the activation of GPR40 attenuates cisplatin-
\end{abstract}

Correspondence to: Professor Soo Wan Kim, Department of Internal Medicine, Chonnam National University Medical School, 42 Jebongro, Dong-gu, Gwangju 501-757, Republic of Korea E-mail: skimw@chonnam.ac.kr

Key words: G-protein-coupled receptor 40, cisplatin, apoptosis, renal tubules induced apoptosis by inhibiting the generation of ROS, the activation of the Src/EGFR/ERK signaling pathway and the nuclear activation of NF- $\mathrm{KB}$ and pro-apoptotic factors.

\section{Introduction}

Cisplatin, a platinum-containing drug, has the ability to bind to DNA, disrupt cell division and ultimately, cause apoptosis. These properties have resulted in the extensive use of cisplatin as an antineoplastic agent. However, its therapeutic usefulness may be limited by the potential risk of acute kidney injury. The apoptotic death of renal proximal tubule epithelial cells is the main characteristic of cisplatin-induced kidney injury $(1,2)$. The activation of pro-apoptotic proteins, mitogen-activated protein kinases (MAPKs), Src/epidermal growth factor receptor (EGFR) and the generation of reactive oxygen species (ROS) have been recognized as the upstream molecular mechanisms responsible for cisplatin-induced apoptosis of renal proximal tubule epithelial cells (3-6). In addition, inflammation, mediated by the activation of nuclear factor- $\kappa \mathrm{B}$ (NF- $\mathrm{kB}$ ), also plays an important role in the pathogenesis of cisplatin-induced apoptosis (7-9).

G-protein-coupled receptor 40 (GPR40) is a member of a subfamily of G-protein-coupled receptors and is abundantly expressed in the pancreatic $\beta$-cells, where it regulates insulin secretion by functioning as a receptor for long-chain free fatty acids $(10,11)$. To date, the expression and function of GPR40 in the kidneys have not been established. Recently, diverse pharmacological effects of GPR40 agonists have been observed (12-16). GPR40 has been emerged as a novel therapeutic target for glycemic control in type 2 diabetes mellitus (12). The anti-diabetic effects of GPR40 agonists have been associated with the improvement of the preservation of pancreatic $\beta$-cells through the inhibition of apoptosis $(13,14)$. In addition, treatment with GPR40 agonists has been shown to suppress cutaneous immune inflammation and prevent NF- $\mathrm{KB}$ activation and nuclear translocation in bone $(15,16)$.

In the present study, we investigated the changes occurring in the expression of GPR40 in the kidneys during cisplatininduced kidney injury. In addition, we investigated the effects of the GPR40 agonist, GW9508, on the cisplatin-induced 
apoptosis of the human renal proximal tubule epithelial cell line, HK-2.

\section{Materials and methods}

Animal model of cisplatin-induced kidney injury. This study was approved by the Ethics Committee of Chonnam National University Medical School, Gwangju, Korea and the experimental procedure conformed to the Institutional Guidelines for Experimental Animal Care and Use. Male Sprague-Dawley rats weighing 180-200 g were injected intraperitoneally with cisplatin ( $8 \mathrm{mg} / \mathrm{kg}$; Boryung Co., Ltd., Ansan, Korea). Control rats were treated with saline. After 2 or 4 days, the rats were anesthetized with ketamine and blood samples were collected from the inferior vena cava. These samples were then analyzed for blood urea nitrogen (BUN) and creatinine levels. The kidneys were rapidly removed from the animals and processed for semi-quantitative immunoblot analysis, as previously described $(17,18)$.

Cell culture and reagents. The HK-2 cells (ATCC; Manassas, VA, USA) were cultured in 100-mm dishes containing Dulbecco's modified Eagle's medium-F-12 (Sigma-Aldrich, St. Louis, MO, USA) supplemented with $10 \%$ fetal bovine serum (FBS), $100 \mathrm{U} / \mathrm{ml}$ of penicillin and $100 \mu \mathrm{g} / \mathrm{ml}$ of streptomycin (Sigma-Aldrich). The cells were grown at $37^{\circ} \mathrm{C}$ in a $5 \% \mathrm{CO}_{2}$ humidified incubator for $24 \mathrm{~h}$ and subcultured to $70-80 \%$ confluence. The cells were treated with cisplatin $(50 \mu \mathrm{M})$ for $24 \mathrm{~h}$ in the presence or absence of the GPR40 agonist, GW9508 (10 $\mu \mathrm{M}$; Cayman Chemical Co., Ann Arbor, MI, USA), for $1 \mathrm{~h}$ prior to the addition of cisplatin and then harvested for further analysis. Control cells were treated with the vehicle (dimethyl sulfoxide).

Cell viability. The HK-2 cells were plated at $5 \times 10^{3}$ cells/well in a 96-well plate and incubated for $24 \mathrm{~h}$. In order to examine the effects of GW9508, the cells were treated with cisplatin for $24 \mathrm{~h}$ in the presence or absence of GW9508 for $1 \mathrm{~h}$ prior to exposure to cisplatin. Cell viability was determined by 3-(4,5-dimethylthiazol-2-yl)-2,5-diphenyltetrazolium bromide (MTT) assay. Following incubation, $50 \mu \mathrm{l}$ of $5 \mathrm{mg} / \mathrm{ml} \mathrm{MTT} \mathrm{(Sigma-Aldrich)}$ were added to each well of the 96 -well plates and followed by incubation for $3 \mathrm{~h}$ at $37^{\circ} \mathrm{C}$. The supernatant was removed by aspiration and then dimethyl sulfoxide was added to dissolve the precipitated dye. The absorbance at $570 \mathrm{~nm}$ was detected using a 96-well ELISA reader (BioTek Instruments Inc., Winooski, VT, USA). Cell viability was expressed as the fraction of surviving cells relative to the vehicle-treated cells.

Detection of apoptosis. Apoptotic nuclei were detected by staining the cells with the DNA-specific fluorescent dye, 4'-6-diamidino-2-phenylindole (DAPI) (Invitrogen, Carlsbad, CA, USA). Following exposure to cisplatin in the presence or absence of GW9508, the cells were fixed with $3 \%$ paraformaldehyde for $30 \mathrm{~min}$ at room temperature and then washed twice with phosphate-buffered saline (PBS). DAPI was added to the fixed cells for $5 \mathrm{~min}$, followed by examination under a fluorescence microscope (Nikon, Tokyo, Japan) in order to assess chromatin condensation and the fragmentation of nuclei. The degree of nuclear fragmentation was evaluated by counting the percentage of apoptotic cells at x400 magnification in 5 randomly selected fields from 3 independent cultures. Furthermore, apoptosis was also assessed by TUNEL assay (Chemicon, Temecula, CA, USA) according to the manufacturer's instructions.

Preparation of nuclear extracts. To prepare the nuclear extracts, the cells were lysed using NE-PER nuclear extraction reagent (NER; Pierce Biotechnology, Rockford, IL, USA) according to the manufacturer's instructions. Briefly, the HK-2 cells incubated with cisplatin in the presence or absence of GW9508 were harvested by scraping the cells into cold PBS, $\mathrm{pH} 7.2$, followed by centrifugation at $14,000 \mathrm{x} \mathrm{g}$ for $2 \mathrm{~min}$. After removing the supernatant, $100 \mu \mathrm{l}$ of ice-cold cytoplasmic extraction reagent (CER) I were added to the dried cell pellets followed by incubation on ice for $10 \mathrm{~min}$. Ice-cold CER II was then added to the tube and centrifuged at 16,000 $\mathrm{x}$ g for $5 \mathrm{~min}$. The pellet fraction was suspended in $50 \mu \mathrm{l}$ of ice-cold NER, followed by centrifugation at $16,000 \mathrm{x}$ g for $10 \mathrm{~min}$. Finally, the supernatant (nuclear extract) fraction was transferred to a new tube and the protein concentrations were measured, as previously described (19).

Semi-quantitative immunoblot analysis. The HK-2 cells were harvested, washed twice with cold PBS, resuspended in lysis buffer (20 mM Tris-HCl, pH 7.4, $0.01 \mathrm{mM}$ EDTA, $150 \mathrm{mM}$ $\mathrm{NaCl}, 1 \mathrm{mM}$ PMSF, $1 \mu \mathrm{g} / \mathrm{ml}$ leupeptin, $1 \mathrm{mM} \mathrm{Na}_{3} \mathrm{VO}_{4}$ ) and sonicated briefly. Following centrifugation, the supernatant was prepared using the Pierce BCA protein assay kit (Pierce Biotechnology) and the protein concentrations were then measured. Equal amounts of protein were separated on 9 or $12 \%$ sodium dodecyl sulfate polyacrylamide gels (SDS-PAGE). The protein contained in the gels was then electrophoretically transferred onto nitrocellulose membranes using a Bio-Rad Mini Protean II apparatus (Bio-Rad Laboratories, Hercules, CA, USA). The blots were subsequently blocked with $5 \%$ milk in a mixture of tris-buffered saline and Tween-20 (TBST; $20 \mathrm{mM}$ Tris-HCl, $140 \mathrm{mM} \mathrm{NaCl}, 0.1 \%$ Tween-20, $\mathrm{pH}$ 8.0) for $1 \mathrm{~h}$ and then incubated overnight at $4^{\circ} \mathrm{C}$ with primary antibodies. The membranes were then incubated with secondary anti-rabbit or anti-mouse horseradish peroxidase-conjugated antibodies and visualized with an enhanced chemiluminescence system.

The anti-GPR40 and anti-caspase 3 antibodies were purchased from Epitomics (Burlingame, CA, USA) and Santa Cruz Biotechnology (Santa Cruz, CA, USA), respectively. The anti-cleaved caspase-3, anti-Bax, anti-Bcl-2, anti-IкB- $\alpha$, anti-NF-кB p65, anti-histone H3, anti-Src, anti-phospho-Src, anti-EGFR, anti-phospho-EGFR, anti-extracellular signalregulated kinase (ERK) and anti-phospho-ERK antibodies were obtained from Cell Signaling Technology (Danvers, MA, USA). All antibodies were diluted in blocking buffer and incubated overnight at $4^{\circ} \mathrm{C}$. Anti- $\beta$-actin (Sigma-Aldrich) antibody was used as a control.

Determination of ROS generation. Intracellular ROS generation was measured using a 2',7'-dichlorodihydrofluorescein diacetate $\left(\mathrm{H}_{2} \mathrm{DCF}-\mathrm{DA}\right)$ fluoroprobe (Molecular Probes, Eugene, OR, USA). The cells were incubated with $5 \mu \mathrm{M}$ $\mathrm{H}_{2} \mathrm{DCF}-\mathrm{DA}$ for $30 \mathrm{~min}$ at $37^{\circ} \mathrm{C}$. The cells were then washed, collected by centrifugation and resuspended in PBS. The fluo- 


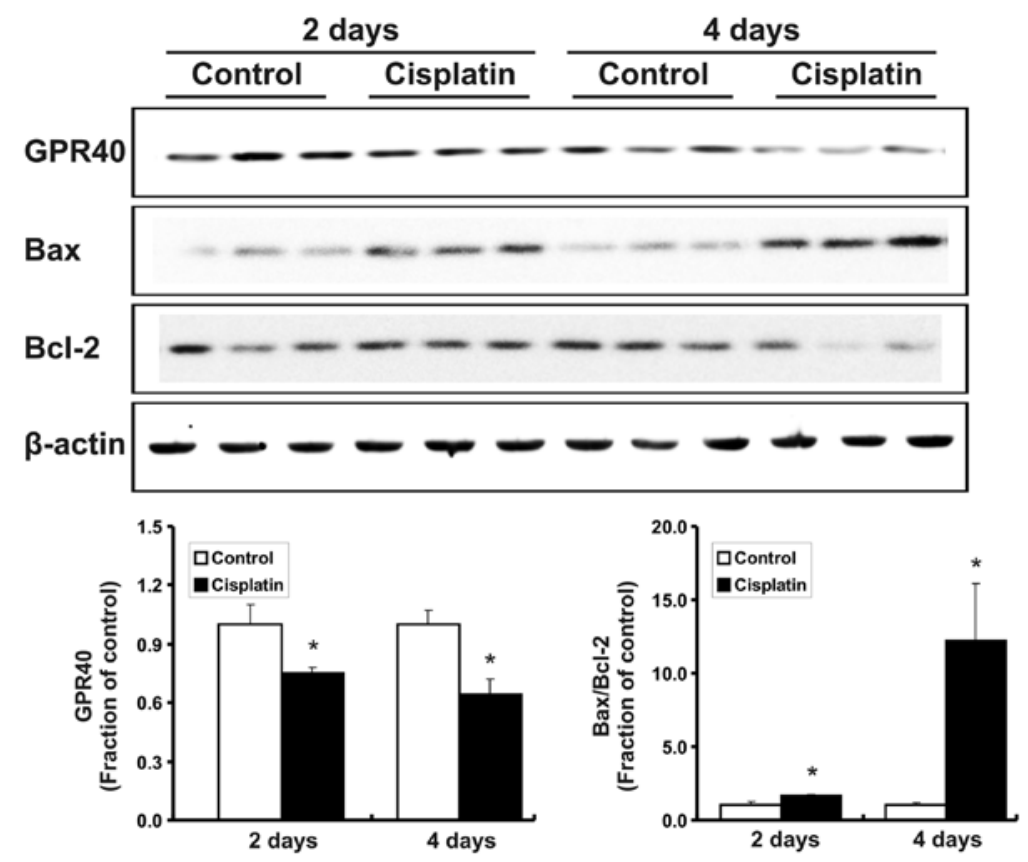

Figure 1. Treatment with cisplatin decreased the protein expression of GPR40 in rat kidneys, while it increased the Bax/Bcl-2 expression ratio. " $\mathrm{P}<0.05$ compared with the control.

rescence intensity was measured using a FACSCalibur ${ }^{\mathrm{TM}}$ flow cytometer (Becton-Dickinson, San Jose, CA, USA).

Statistical analysis. The results are expressed as the means \pm standard error of the mean (SEM) of 3 individual experiments. An unpaired t-test was used to determine the differences between 2 groups. Multiple comparisons among the groups were made using one-way ANOVA and the post hoc Tukey HSD test. Differences with values of $\mathrm{P}<0.05$ were considered statistically significant.

\section{Results}

Expression of GPR40 in kidneys. Treatment with cisplatin increased serum creatinine levels in the rats compared with the control (after 2 days, $0.22 \pm 0.02$ vs. $0.43 \pm 0.06 \mathrm{mg} / \mathrm{dl}, \mathrm{P}<0.05$; after 4 days, $0.25 \pm 0.02$ vs. $3.89 \pm 0.26 \mathrm{mg} / \mathrm{dl}, \mathrm{P}<0.05)$. BUN levels were also increased in the cisplatin-treated rats (after 2 days, $16.45 \pm 0.57$ vs. $29.04 \pm 2.19 \mathrm{mg} / \mathrm{dl}, \mathrm{P}<0.05$; after 4 days, $15.60 \pm 1.24$ vs. $204.24 \pm 10.46 \mathrm{mg} / \mathrm{dl}, \mathrm{P}<0.05$ ). Following cisplatin treatment, the protein expression of GPR40 was decreased in the kidneys of the rats, while the $\mathrm{Bax} / \mathrm{Bcl}-2$ expression ratio was increased (Fig. 1).

Cell viability and apoptosis. We performed an MTT assay to determine the viability of the HK-2 cells. Our data revealed that treatment with cisplatin decreased the viability of the cells compared with the control. Furthermore, pre-treatment with GW9508 attenuated the cisplatin-induced cell death (Fig. 2). DAPI staining indicated that treatment with cisplatin increased the number of cells with condensed nuclei and TUNEL staining also demonstrated that treatment with cisplatin resulted in increased levels of apoptosis. However, pre-treatment with GW9508 prevented the cisplatin-induced apoptosis of HK-2 cells (Fig. 3). Treatment with cisplatin also

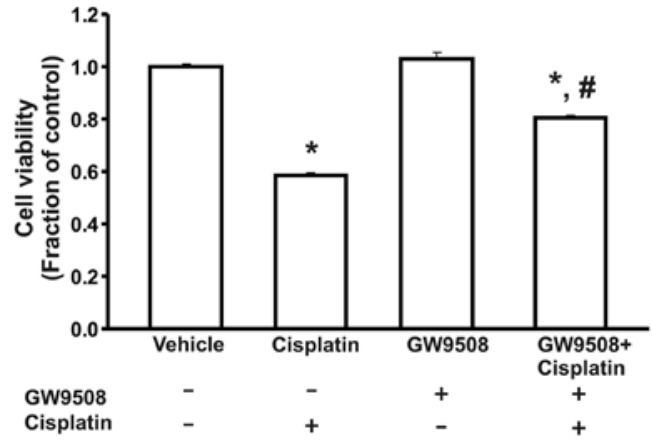

Figure 2. MTT assay revealed that treatment with cisplatin decreased the viability of HK-2 cells. Pre-treatment with GW9508, a GPR40 agonist, attenuated the effects of cisplatin on cell viability. ${ }^{*} \mathrm{P}<0.05$ compared with the vehicletreated HK-2 cells. ${ }^{\#} \mathrm{P}<0.05$ compared with the cisplatin-treated HK-2 cells.

increased the expression of cleaved caspase- 3 and the Bax/ Bcl-2 expression ratio in the HK-2 cells compared with the control. These changes were attenuated by pre-treatment with GW9508 (Fig. 4).

$N F-\kappa B$ expression. During activation, NF- $\mathrm{NB}$ is released from the inhibitory subunit IкB- $\alpha$, and translocates to the nucleus, where it promotes the transcriptional activation of a number of target genes. Importantly, the protein expression of the p65 subunit of nuclear NF- $\mathrm{KB}$ was markedly increased in the cisplatin-treated HK-2 cells compared with the control, while the expression of cytosolic IкB- $\alpha$ was decreased. Furthermore, the apparent increase in NF- $\mathrm{KB}$ nuclear translocation induced by treatment with cisplatin was counteracted by pre-treatment with GW9508 (Fig. 5).

ROS generation and the Src/EGFR/ERK signaling pathway. We measured the intracellular ROS generation using 


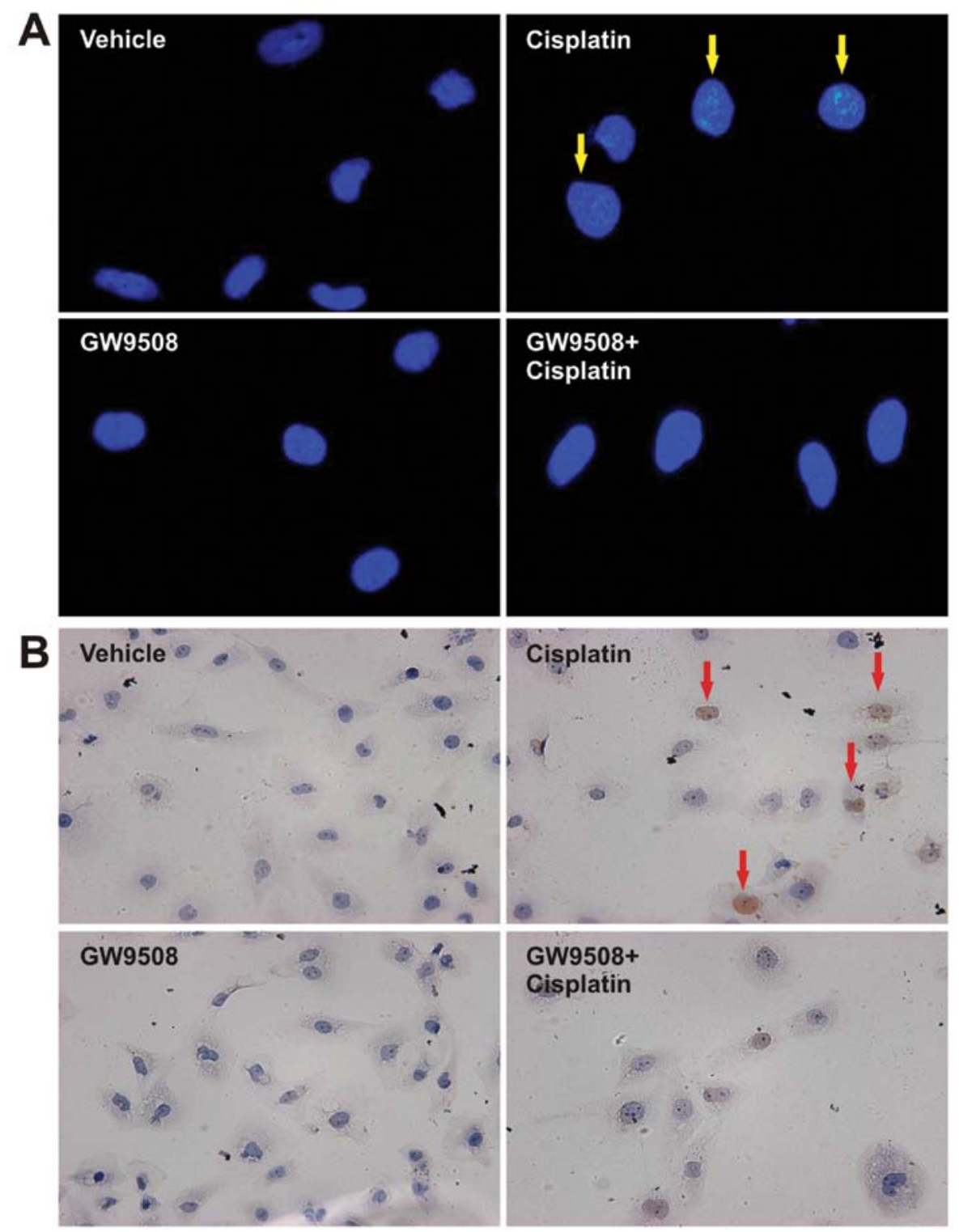

Figure 3. (A) DAPI staining revealed that treatment with cisplatin increased the number of cells with condensed nuclei, which was suppressed by pre-treatment with GW9508, a GPR40 agonist. (B) TUNEL staining also revealed that pre-treatment with GW9508 prevented the cisplatin-induced apoptosis of HK-2 cells.

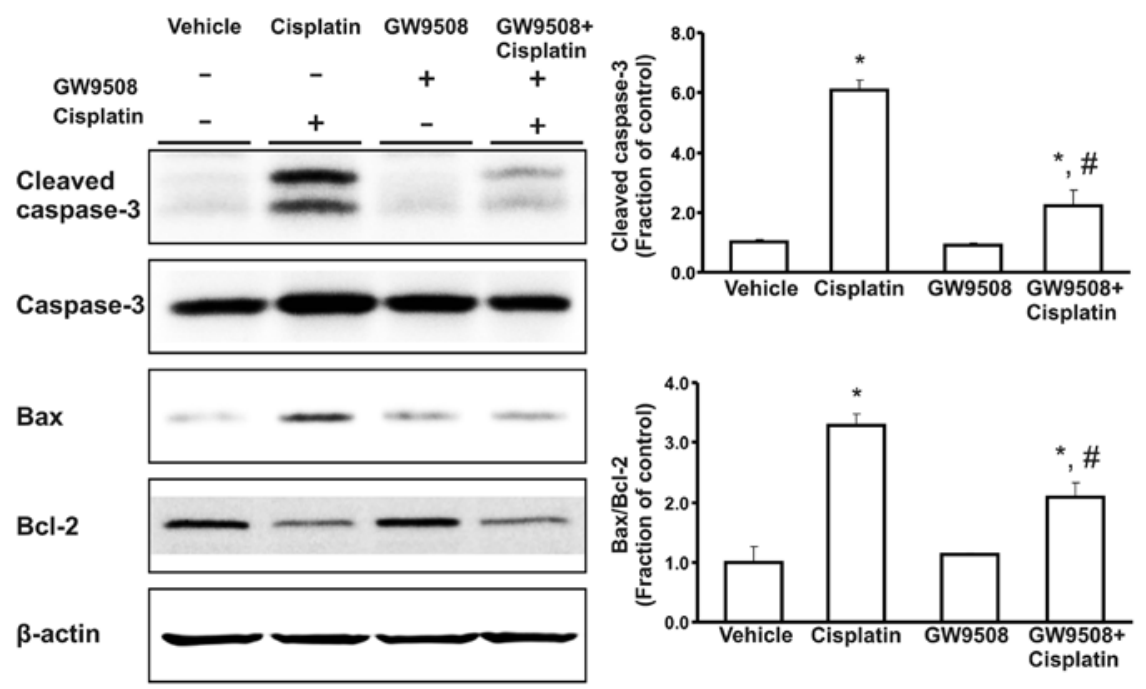

Figure 4. Treatment with cisplatin increased the expression of pro-apoptotic proteins. These changes were counteracted by pre-treatment with GW9508, a GPR40 agonist. " $\mathrm{P}<0.05$ compared with the vehicle-treated HK-2 cells. ${ }^{*} \mathrm{P}<0.05$ compared with the cisplatin-treated HK-2 cells. 


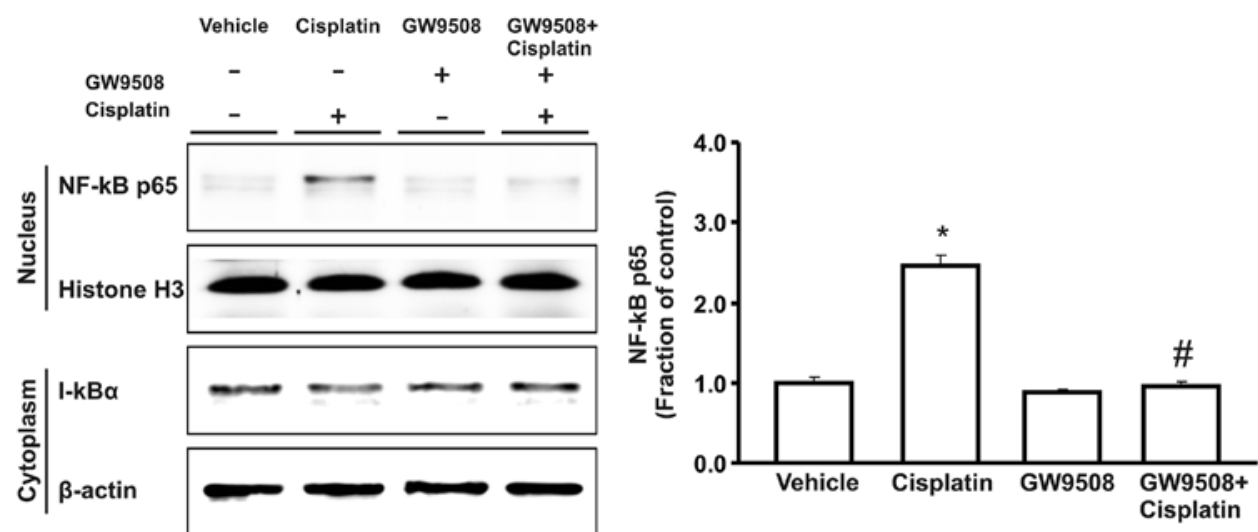

Figure 5. Cisplatin-induced activation of the NF- $\mathrm{BB}$ subunit p65 was counteracted by pre-treatment with GW9508, a GPR40 agonist. "P<0.05 compared with the vehicle-treated HK-2 cells. ${ }^{*} \mathrm{P}<0.05$ compared with the cisplatin-treated HK-2 cells.
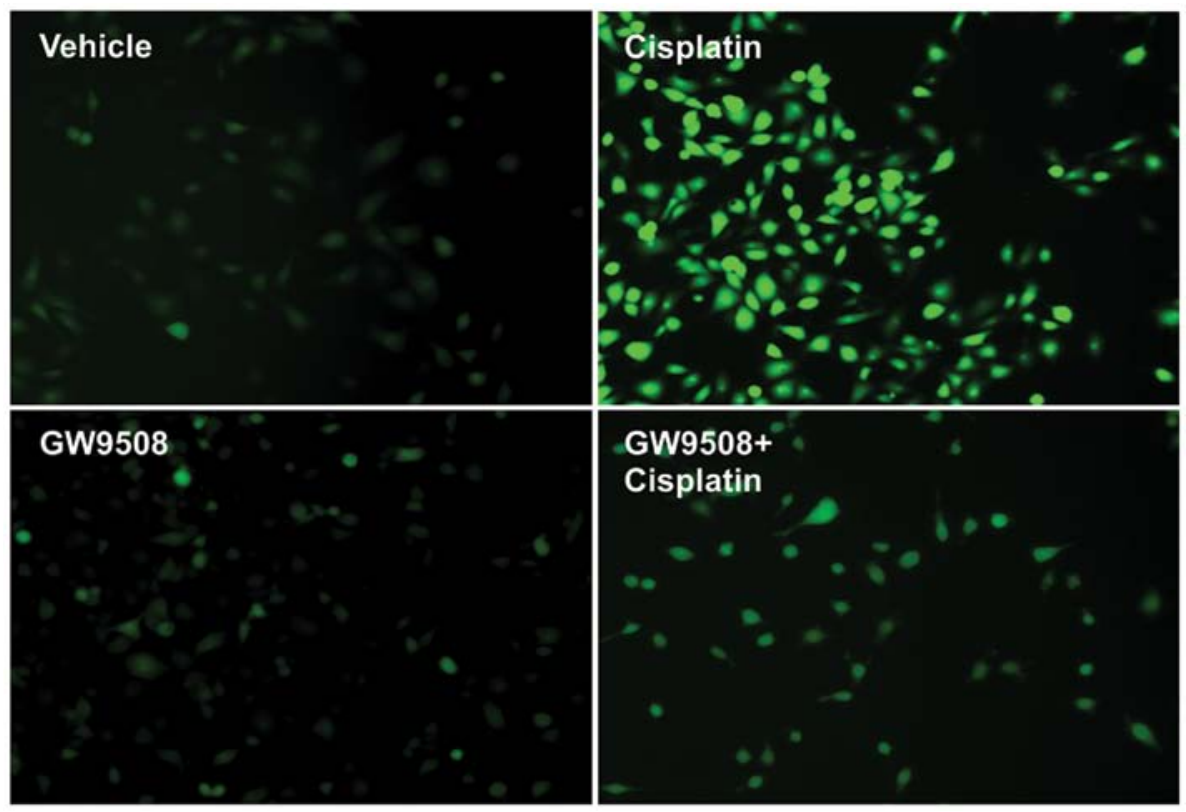

Figure 6. DCF-DA staining indicated that the cisplatin-induced generation of ROS was inhibited by pre-treatment with GW9508, a GPR40 agonist.

$\mathrm{H}_{2} \mathrm{DCF}-\mathrm{DA}$ fluoroprobe following treatment with cisplatin in the absence or presence of pre-treatment with GW9508. We observed that treatment with cisplatin promoted the generation of ROS in the HK-2 cells. However, this increase was diminished by pre-treatment of the cells with GW9508 (Fig. 6). Furthermore, following treatment with cisplatin, the expression of the phosphorylated proteins of Src, EGFR and ERK was markedly increased compared with the control. Pre-treatment with GW9508 counteracted this increase in the phosphorylation of the Src/EGFR/ERK signaling pathway (Fig. 7).

\section{Discussion}

Previously, we, as well as others have demonstrated that treatment with cisplatin induces the apoptosis of renal proximal tubule epithelial cells, and that the activation of pro-apoptotic proteins is causally related to the pathogenesis of cisplatininduced kidney injury $(17,20,21)$. Our findings in the present study also confirmed that treatment with cisplatin impaired renal functional parameters and increased the Bax/Bcl-2 expression ratio in the kidneys.

It has been demonstrated that GPR40 is primarily expressed in pancreatic $\beta$-cells, where it regulates the physiological effects of fatty acids as a cell-surface receptor $(11,22)$. However, its cellular localization and physiological function in the kidneys have not yet been established. In the present study, we demonstrated that GPR40 was expressed in rat kidneys and that treatment with cisplatin resulted in a decrease in the protein expression of GPR40. This decrease was also associated with an increase in serum creatinine and BUN levels and an increase in the Bax/Bcl- 2 expression ratio. Taken together, these data suggest that the decreased expression of GPR40 in the kidneys may be related to the pathogenesis of cisplatin-induced kidney injury.

To the best of our knowledge, the anti-apoptotic effects of GPR40 agonists on renal tubular epithelial cells have not been 

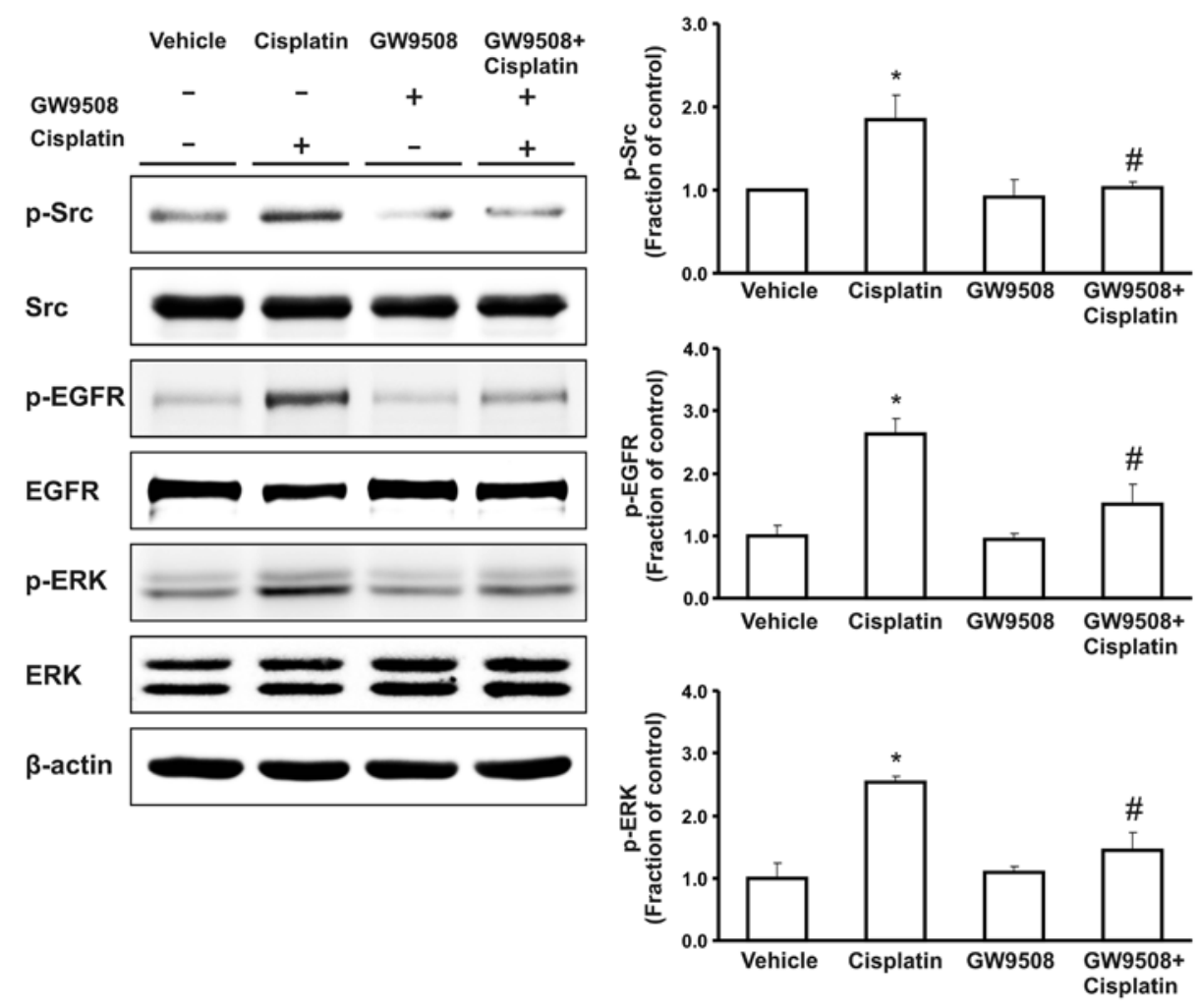

Figure 7. Pre-treatment with GW9508, a GPR40 agonist, counteracted the increased phosphorylation of Src, EGFR and ERK induced by treatment with cisplatin. " $\mathrm{P}<0.05$ compared with the vehicle-treated HK-2 cells. ${ }^{~} \mathrm{P}<0.05$ compared with the cisplatin-treated HK-2 cells.

demonstrated to date, although recent studies have revealed that GPR40 agonists inhibit the apoptosis of pancreatic $\beta$-cells $(13,14)$. In the present study, treatment with cisplatin decreased the viability of HK-2 cells and increased apoptosis, which was associated with the increased expression of pro-apoptotic proteins. These changes were attenuated by pre-treatment with the GPR40 agonist, GW9508. The present study suggests that GPR40 agonists play a protective role in the cisplatin-induced apoptosis of renal tubular epithelial cells through the inhibition of pro-apoptotic proteins. Furthermore, it has been established that the activation of NF- $\mathrm{\kappa B}$ plays a critical role in the pathogenesis of cisplatin-induced kidney injury and the inhibition of NF- $\mathrm{KB}$ activity has been shown to attenuate the apoptosis of renal tubular epithelial cells (7-9). The present study also demonstrated that treatment with cisplatin increased the nuclear translocation of NF- $\mathrm{\kappa B}$ in HK-2 cells. In addition, our data indicate that the GPR40 agonist, GW9508, counteracted the cisplatin-induced activation of $\mathrm{NF}-\mathrm{\kappa B}$ and prevented cisplatin-induced apoptosis.

Increased levels of ROS also play a crucial role in the development of cisplatin-induced kidney injury. Cisplatin leads to the accumulation of endogenous ROS in renal tubular epithelial cells through the depletion of glutathione and the induction of mitochondrial dysfunction $(1,2)$. The inhibition of cisplatin-induced generation of ROS diminishes cisplatininduced apoptosis $(6,9,23,24)$. In the present study, we also demonstrated that treatment with cisplatin increased the generation of ROS in HK-2 cells, which was suppressed by pre-treatment with GW9508, a GPR40 agonist. This finding suggests that the protective role of the GPR40 agonist
(GW9508) against cisplatin-induced apoptosis may be attributed to the inhibition of ROS generation.

The activation of the Src/EGFR/ERK signaling pathway is known to affect a number of processes, including cellular proliferation, differentiation and apoptosis. Recent studies have suggested that prolonged generation of ROS triggers the activation of the Src/EGFR/ERK signaling pathway $(25,26)$. The phosphorylation of Src and EGFR has been shown to result in the activation of ERK, which plays a pro-apoptotic role as an upstream mechanism of pro-apoptotic proteins during cisplatin-induced kidney injury (3-5). In the present study, we demonstrted that pre-treatment with the GPR40 agonist, GW9508, counteracted the cisplatin-induced increase in the phosphorylation of Src/EGFR/ERK, which may be associated with the anti-apoptotic effects of the GPR40 agonist.

In conclusion, the data from our study demonstrate that GPR40 expression in the kidneys is decreased in rats with cisplatin-induced kidney injury. In HK-2 cells, the activation of GPR40 attenuates cisplatin-induced apoptosis by inhibiting ROS generation, the activation of the Src/EGFR/ERK signaling pathway and the nuclear activation of NF- $\kappa \mathrm{B}$ and pro-apoptotic factors.

\section{Acknowledgements}

The present study was supported by a research grant from the Research Institute of Medical Sciences, Chonnam National University (2012-CURIMS-DR002), Chonnam National University (2013-2575) and the Chonnam National University Hospital Biomedical Research Institute (CRI14012-1). 


\section{References}

1. Yao X, Panichpisal K, Kurtzman N and Nugent K: Cisplatin nephrotoxicity: a review. Am J Med Sci 334: 115-124, 2007.

2. Pabla $\mathrm{N}$ and Dong Z: Cisplatin nephrotoxicity: mechanisms and renoprotective strategies. Kidney Int 73: 994-1007, 2008

3. Arany I, Megyesi JK, Kaneto H, Price PM and Safirstein RL: Cisplatin-induced cell death is EGFR/src/ERK signaling dependent in mouse proximal tubule cells. Am J Physiol Renal Physiol 287: F543-F549, 2004.

4. Jo SK, Cho WY, Sung SA, Kim HK and Won NH: MEK inhibitor, U0126, attenuates cisplatin-induced renal injury by decreasing inflammation and apoptosis. Kidney Int 67: 458-466, 2005.

5. Kim YK, Kim HJ, Kwon CH, Kim JH, Woo JS, Jung JS and Kim JM: Role of ERK activation in cisplatin-induced apoptosis in OK renal epithelial cells. J Appl Toxicol 25: 374-382, 2005.

6. Mishima K, Baba A, Matsuo M, Itoh Y and Oishi R: Protective effect of cyclic AMP against cisplatin-induced nephrotoxicity. Free Radic Biol Med 40: 1564-1577, 2006

7. Li S, Gokden N, Okusa MD, Bhatt R and Portilla D: Antiinflammatory effect of fibrate protects from cisplatin-induced ARF. Am J Physiol Renal Physiol 289: F469-F480, 2005.

8. Lee S, Kim W, Moon SO, et al: Rosiglitazone ameliorates cisplatin-induced renal injury in mice. Nephrol Dial Transplant 21: 2096-2105, 2006.

9. Sung MJ, Kim DH, Jung YJ, et al: Genistein protects the kidney from cisplatin-induced injury. Kidney Int 74: 1538-1547, 2008.

10. Sum CS, Tikhonova IG, Neumann S, Engel S, Raaka BM, Costanzi S and Gershengorn MC: Identification of residues important for agonist recognition and activation in GPR40. J Biol Chem 282: 29248-29255, 2007.

11. Itoh Y, Kawamata Y, Harada M, et al: Free fatty acids regulate insulin secretion from pancreatic beta cells through GPR40. Nature 422: 173-176, 2003.

12. Bharate SB, Nemmani KV and Vishwakarma RA: Progress in the discovery and development of small-molecule modulators of G-protein-coupled receptor 40 (GPR40/FFA1/FFAR1): an emerging target for type 2 diabetes. Expert Opin Ther Pat 19: 237-264, 2009.

13. Gowda N, Dandu A, Singh J, et al: Treatment with CNX-011-67, a novel GPR40 agonist, delays onset and progression of diabetes and improves beta cell preservation and function in male ZDF rats. BMC Pharmacol Toxicol 14: 28, 2013.

14. Wagner R, Kaiser G, Gerst F, et al: Reevaluation of fatty acid receptor 1 as a drug target for the stimulation of insulin secretion in humans. Diabetes 62: 2106-2111, 2013.
15. Fujita T, Matsuoka T, Honda T, Kabashima K, Hirata T and Narumiya S: A GPR40 agonist GW9508 suppresses CCL5, CCL17, and CXCL10 induction in keratinocytes and attenuates cutaneous immune inflammation. J Invest Dermatol 131: 1660-1667, 2011.

16. Wauquier F, Philippe C, Léotoing L, et al: The free fatty acid receptor $\mathrm{G}$ protein-coupled receptor 40 (GPR40) protects from bone loss through inhibition of osteoclast differentiation. J Biol Chem 288: 6542-6551, 2013.

17. Kim SW, Lee JU, Nah MY, Kang DG, Ahn KY, Lee HS and Choi KC: Cisplatin decreases the abundance of aquaporin water channels in rat kidney. J Am Soc Nephrol 12: 875-882, 2001.

18. Ma SK, Choi JS, Joo SY, et al: Activation of the renal PI3K/Akt/ mTOR signaling pathway in a DOCA-salt model of hypertension. Chonnam Med J 48: 150-154, 2012.

19. Rosenau C, Emery D, Kaboord B and Qoronfleh MW Development of a high-throughput plate-based chemiluminescent transcription factor assay. J Biomol Screen 9: 334-342, 2004.

20. Bae EH, Lee J, Ma SK, et al: alpha-Lipoic acid prevents cisplatininduced acute kidney injury in rats. Nephrol Dial Transplant 24: 2692-2700, 2009.

21. Park JW, Cho JW, Joo SY, et al: Paricalcitol prevents cisplatininduced renal injury by suppressing apoptosis and proliferation. Eur J Pharmacol 683: 301-309, 2012.

22. Briscoe CP, Tadayyon M, Andrews JL, et al: The orphan $\mathrm{G}$ protein-coupled receptor GPR40 is activated by medium and long chain fatty acids. J Biol Chem 278: 11303-11311, 2003.

23. Lee S, Moon SO, Kim W, et al: Protective role of L-2-oxothiazolidine-4-carboxylic acid in cisplatin-induced renal injury. Nephrol Dial Transplant 21: 2085-2095, 2006.

24. Mukhopadhyay P, Horváth B, Zsengellér Z, et al: Mitochondrialtargeted antioxidants represent a promising approach for prevention of cisplatin-induced nephropathy. Free Radic Biol Med 52: 497-506, 2012.

25. Chen J, Chen JK, Nagai K, et al: EGFR signaling promotes TGF $\beta$-dependent renal fibrosis. J Am Soc Nephrol 23: 215-224, 2012.

26. Chen J, Chen JK and Harris RC: Angiotensin II induces epithelialto-mesenchymal transition in renal epithelial cells through reactive oxygen species/Src/caveolin-mediated activation of an epidermal growth factor receptor-extracellular signal-regulated kinase signaling pathway. Mol Cell Biol 32: 981-991, 2012. 